varying over a range of about $3 \cdot 55970 \pm 0.00020$ $\mathrm{kX}$. (at $18^{\circ} \mathrm{C}$.), the limits of error for any one diamond being \pm 0.05 X.U. ( $1 \mathrm{kX} .=1000$ X.U.). The upper limit of my measurements $(3 \cdot 55990 \pm$ $0.00005 \mathrm{kX}$.) was found for a diamond which had been so blackened by heat-treatment that it was almost opaque; although its Laue photograph showed also the powder lines of graphite (the graphite flecks extending throughout the volume of the crystal) it remained nevertheless a good single crystal of diamond, type II. The lattice constants of the two types of diamond showed no consistent variation.

Davy Faraday Laboratory, KathleEN LoNSDaLe.

Royal Institution, London, W.1.

NATURe, 151, 52 (1943).

\section{Secondary Non-Laue Reflexions from Phloroglucine Dihydrate}

Dr. LONSDALE ${ }^{1}$ found a type of non-Laue reflexion from diamond which is different from the usual type of diffuse spots, and she mentions them as secondary extra reflexions. The spots of this type are, as distinguished from the primary type, extremely sharp for a special orientation of the crystal with respect to the incident beam, and may occasionally be drawn out into streaks as the crystal deviates from this orientation. Non-radial streaks in monochromatic X-rays have also been found by Lonsdale and Smith $^{2}$ in the case of benzil.

In a rotation photograph of phloroglucine dihydrate crystal about its $c$-axis, it was found that continuous streaks appeared connecting the spots on row lines. On oscillating the crystal through narrow angular ranges, these streaks became more prominent, but they appeared as broken short lengths corresponding to the range of oscillation. The very slow falling off of intensity along the lengths of these streaks indicated clearly that superposed on the regular crystal lattice there was an effect showing a breaking up of lattice along the $c$-axis, while along the $a$ and the $b$ axes the crystal was perfectly regular. That is equivalent to saying that, in the Laue equations : $a_{0}\left(\alpha_{0}-\alpha\right)=h \lambda, b_{0}\left(\beta_{0}-\beta\right)=k \lambda$, and $c_{0}\left(\gamma_{0}-\gamma\right)=l \lambda$, the first and the second equations remain true, while in the third there is a randomness superposed on the regular periodicity along $c$. Hence if one takes a Laue photograph with $\mathrm{X}$-ray beam incident along the $c$-axis, one would expect to obtain cross-grating diffraction spots. This was indeed found on taking such a photograph. Actual calculations showed that the positions of these diffraction spots agreed accurately with those obtained from the first two Laue equations for both the copper $K \alpha$ and copper $K \beta$ radiations (except when $h=0$ or $k=0$ ), and these are extremely sharp, in fact showing the exact shape of the irradiated crystal. Laue photographs with the $\mathrm{X}$-ray beam along $b$ and $c$ directions also confirm this breaking up of the periodicity along the $c$-axis alone.

These diffraction effects occur over and above the ordinary diffuse reflexions, which are much weaker than is usual for organic crystals, except that the reflexion corresponding to the plane (201) is very strong.

It is very remarkable that the central parts of these secondary spots are quite clear. That this is a real effect has been proved by using a number of different crystals of various sizes and from different crops. This clear centre is not present, however, in the case of the Bragg reflexions, either from oscillation photographs or Laue photographs, or in the case of primary extra reflexions. That the secondary reflexions are produced by the outer parts of the crystal and not by the central portion has been substantiated by taking a Laue photograph from a crystal cut along a diagonal as well as by allowing a very narrow beam to be incident on the central part of the crystal only. In the former case, the secondary diffraction spots are of a triangular shape with the middle of the side corresponding to the cut diagonal clear, while in the latter case these spots completely vanished.

Indian Association for the

Advancement of Science, 210 Bowbazar Street, Calcutta.

K. BANERJEE.

Physics Laboratory,

University, Dacca.

1 Proc. Roy. Soc., A, 179, 8 (1941).

'Proc. Roy. Soc., A, 179, 315 (1941).

C. R. Bose.

\section{Abnormal Dissociation in Flame Gases}

Some experiments have recently been made with a flow calorimeter consisting, essentially, of a vertical water-jacketed tube fitted with a burner the height of which could be varied at will. Two similar resistance thermometers, one consisting of a plain platinum. rhodium wire and the other a quartz-coated wire, each being of the same overall diameter of 0.0005 in., were placed side by side in the gas stream. The products from the flame could be cooled to any required extent before passing the wires by raising or lowering the burner.

The results of a series of experiments with the burner at different heights to give different degrees of cooling of the flame gases are shown in the accompanying table. The mixture supplied to the burner was 25 per cent carbon monoxide plus 75 per cent air in all cases.

\begin{tabular}{|c|c|c|c|c|c|}
\hline $\begin{array}{c}\text { Experi- } \\
\text { ment } \\
\text { No. }\end{array}$ & $\begin{array}{c}\text { Distance } \\
\text { of burner } \\
\text { to wires } \\
\text { (in.) }\end{array}$ & $\begin{array}{c}\text { Approxi- } \\
\text { mate time } \\
\text { for gases } \\
\text { to reach } \\
\text { wires } \\
\text { (sec.) }\end{array}$ & $\begin{array}{c}\text { Quartz- } \\
\text { coated wire } \\
\text { tempera- } \\
\text { ture } \\
\left({ }^{\circ} \mathrm{C} .\right)\end{array}$ & $\begin{array}{c}\text { Plain } \\
\text { wire tem- } \\
\text { perature } \\
\left({ }^{\circ} \mathrm{C} .\right)\end{array}$ & $\begin{array}{c}\text { Difference } \\
\text { in temp. } \\
\text { of two } \\
\text { wires } \\
\left({ }^{\circ} \mathrm{C} .\right)\end{array}$ \\
\hline 1 & 1.5 & $0 \cdot 2$ & 1020 & 1180 & 160 \\
2 & $3 \cdot 5$ & $0 \cdot 4$ & 960 & 1080 & 120 \\
3 & $5 \cdot 5$ & $0 \cdot 7$ & 870 & 980 & 110 \\
4 & $7 \cdot 5$ & 0.9 & 800 & 870 & 70 \\
5 & $9 \cdot 5$ & 1.2 & 730 & 770 & 40 \\
6 & $13 \cdot 5$ & 1.6 & 570 & 570 & 0 \\
7 & 17.5 & 2.1 & 420 & 420 & 0 \\
\hline
\end{tabular}

It will be noted that there is a marked difference in the two temperatures, the plain wire consistently giving the higher value. This is clearly due to the phenomenon of abnormal dissociation ${ }^{1}$. The interesting fact, however, in these experiments is that the difference in the temperatures recorded by the two thermometers persists until the gas temperature is reduced to about $500^{\circ} \mathrm{C}$. This corresponds to the lapse of about $1 \frac{1}{2} \mathrm{sec}$. after combustion.

Thus it is established that abnormal dissociation can persist in flame gases when they have been subjected to considerable cooling.

The exact time and temperature at which the two thermometers will record the same temperature, thus 